exotic species will succeed or fail purely from a comparison of conditions in their native land with those in the locality of introduction.

As an example, the Monterey pine, Pinus radiata, from a restricted area in California, has been outstandingly successful in New Zealand, many parts of Australia, in South Africa, Spain and Chile, and it even grows well in the highlands of Kenya. Again, the Serbian spruce, Picaea omorika, which grows on limestone mountains in a very restricted area in Yugoslavia, grows remarkably well on acid peats in Scotland. In other cases, the reverse may be true, and many species which have a wide natural range, like the Douglas fir or European larch, have developed local strains which are susceptible to the conditions under which they are grown. The only safe way of selecting a species for introduction is to try it, and all large-scale plantings of exotic trees have been preceded by species trials in arboreta or small trial plots where suitability to the locality is tested, followed by larger plot tests on a more limited range of sites where performance can be estimated.

There are many doubts and risks in introducing an exotic species into a new habitat, and it should always be a principle first to see whether any indigenous species will fulfil the objects in view. The principle that one should not consider introducing an exotic species on a large scale if there is an indigenous species that will meet requirements is generally true. In countries like Britain, however, where the only native timber-yielding conifer, the Scots pine, grows relatively slowly, there is a good case for introducing species that will give higher yields. It is fortunate that some of the conifers from the west coast of North America, Sitka spruce, Douglas fir, western hemlock and lodgepole pine, as well as some from Europe, such as Corsican pine, Norway spruce, European larch and, more remotely, the Japanese larch, have proved so successful in Britain. Trials have shown that many species, particularly those from the eastern parts of North America, suffer so seriously from late-spring frosts in Britain as to be not worth growing. Most species of Eucalyptus are found to be too susceptible to frost to be grown safely in Britain, except in sheltered parts of Devon and Cornwall. Corsican pine, when moved to northern British latitudes, is found to be restricted in the elevation at which it can be grown. Teak does not grow well on very heavy soils or on laterites in the tropics and needs some lime in the soil; it seems to require a definite dry season when it is leafless. No amount of information can enable a species to be accepted as safe for large-scale planting without extensive trials.

It frequently happens that a particular species is so superior in performance to all others tried that there is a tendency to rely on it alone in large plantation programmes. This has occurred, for example, in New Zealand and parts of Australia where Pinus radiata has been planted extensively. So far there has been no serious trouble, but there is always the danger that something may go wrong. It is advisable to have one or more alternative species to fall back on in an emergency.

In South Africa, for example, $P$. radiata, which showed great promise to start with, has more recently suffered severely from a fungal disease which kills the leading shoot. There is now a tendency to prefer $P$. patula, another fast-growing pine, which does not suffer from this defect.

\title{
ERADICATION OF MALARIA IN EAST AFRICA
}

$\mathrm{N}$ the annual report of the East African Council for Medical Research*, the director of the East African Institute of Malaria and Vector-Borne Diseases, Dr. G. Pringle, describes how a draft plan has been prepared for the eradication of malaria from East Africa, based on a combined attack with drugs as well as insecticides. The plan has already received critical examination by a meeting of experts held in Tanga, and further inter-territorial consultations are planned.

In the Taveta-Para area, whore spraying with dieldrin was discontinued early in 1959 , a close watch on malaria incidence has been kept. Anopheles gambiae has shown a marked increase in numbers, although house catches have still been less than prespraying densities. The longevity of this vector is still reduced, indicating the presence of some continuing insecticidal effect. A. funestus, which was almost certainly eradicated from the area, has not reappeared. Although parasite densities are not back to former levels, there has been a major resurgence of the disease in the swampside villages. Studies of the serum $\gamma$-globulin levels in schoolchildren also indicate that an effective immunity has yet to be acquired.

* East African High Commission. The East African Council for Medical Research-Annual Report, 1960/61. Pp. ii +16. (Nairobi: Government Printer, 1961.) 28.
The feeding preference of $A$. gambiae, in areas where man and cattle aro both attacked, has been studied with the view of finding out whether the individual mosquitoes show a consistent tendeney to feed on one or other host. Results in one area are still inconclusive, but in another district the presence of normal infection-rates in insects caught feeding on cattle clearly showed that the same mosquitoes had fed at different times on both available hosts. Thus, so far, no evidence has been found of two co-existing strains of $A$. gambiae, differing in their feeding habits, and hence probably in their response to insecticides.

Among potential secondary vectors of malaria, infections have been found in $A$. pharoensis and $A$. squamosus, but none in the more abundant and ubiquitous members of the A. coustani group. Agegrouping studies indicate that, in all these species of exophilic mosquitoes, longevity is greatly reduced compared with the main house resting vectors.

A flourishing colony of the coastal salt water form of A. gambiae has been established. Crossing experiments with two strains of fresh water $A$. gambiae have shown that, although occasional fertile offspring are produced, a formidable barrier to gene exchange exists. Thus reproductive isolation of the two groups in Nature seems likely, although proof of this has yet to be obtained in the field. 